\title{
Historia de un latifundio rioplatense: las estancias de Riblos en Areco, 1713-1813.
}

\author{
Carlos María Birocco
}

Universidad de Morón.

Provincia de Buenos Aires, Argentina

\begin{abstract}
Uno de los aspectos más debatidos por los historiadores del período colonial en la Argentina ha sido el de la extensión media de la propiedad rural en el Buenos Aires del siglo XVIII. Con el propósito de ilustrar la existencia de la propiedad latifundiaria en dicha región y período, se reconstruirá en este artículo la historia de uno de esos grandes dominios, el de Miguel de Riblos en el pago de Areco, que con escasos recortes territoriales se conservó en poder de sus descendientes hasta las primeras décadas del siglo XIX. Mediante el seguimiento de esta familia rioplatense de terratenientes a lo largo de una centuria se analizarán los cambios que experimentó la administración de una gran finca rural en su adaptación a diferentes coyunturas, como también las estrategias a través de las cuales se buscó evitar el fraccionamiento de la propiedad.
\end{abstract}

Desde mediados de la década de 1980, la historia rural del período colonial ha gozado en la Argentina de especial relevancia en el debate historiográfico. Uno de los aspectos más largamente discutidos ha sido el de la extensión media de la propiedad, especialmente en lo que toca a la importancia del latifundio y de la figura del gran propietario en el Buenos Aires del siglo XVIII. Autores como Juan Carlos Garavaglia y Carlos Mayo, entre otros, han postulado la debilidad del latifundio colonial, a la vez que negaron la existencia de una élite terrateniente dominante en el ámbito rural a consecuencia de un proceso de diferenciación incompleto respecto de la élite mercantil, o bien de la preminencia de ésta sobre los sectores rurales. Otros, como Eduardo Azcuy Ameghino, han dedicado importantes estudios a demostrar el predominio de la gran propiedad, que poseía un carácter acentuadamente latifundiario en la frontera con el indígena, y han hecho hincapié en el carácter preponderantemente terrateniente de la propiedad del suelo. ${ }^{1}$

1 En la polémica mencionada se destacan Azcuy Ameghino, Eduardo: El latifundio y la gran propiedad colonial rioplatense. Buenos Aires, 1995; Azcuy Ameghino, Eduardo y Martínez Dougnac, Gabriela: Tierra y ganado en la campaña de Buenos Aires según los censos de hacendados de 1789. Buenos Aires, 1989; Gresores, Gabriela y Martínez Dougnac, Gabriela: "En torno a la economía y la sociedad rioplatense en el siglo XVIII", en Ciclos, año II, vol. II, núm. 3, Buenos Aires, 1992, págs. 173-195. En una posición divergente a los anteriores, véase Garavaglia, Juan Carlos: "Las estancias en la Campaña de Buenos Aires. Los medios de producción”, en Fradkin, Raúl (Comp.): La histo- 
A nuestro entender, la propiedad latifundiaria gozó de un peso indiscutible en el Buenos Aires colonial. Con el propósito de ilustrarlo, reconstruiremos la historia de uno de esos grandes dominios, el de Miguel de Riblos en el pago de Areco. Llegado al Río de la Plata desde su Navarra natal con plaza de soldado, Riblos logró promocionarse socialmente gracias a un ventajoso matrimonio con la hija de un mercader portugués, Gregoria Silveyra Gouvea. La dote de su mujer comprendía, entre otros inmuebles, una suerte de estancia sobre el río Areco, a la cual él añadiría por compra otras suertes linderas. Quedó de esa forma en propiedad de un enorme triángulo de unas 15 leguas cuadradas de superficie que tenía por límites dicho río, el camino de Buenos Aires a Santa Fe y el arroyo de la Cañada Honda. Esta enorme rinconada estaba poblada por miles de equinos en estado semisalvaje que sirvieron como reserva de yeguas de vientre a sus seis puestos de cría de mulas, que eran asistidos por esclavos y peones.

A principios del siglo XVIII, Riblos se convirtió en el más destacado criador y acopiador de ganado mular de la ciudad de Buenos Aires. Con el objeto de colocar sus tropas en el Perú montó una compañía con el mercader Juan de Beytía y Aguirre, miembro del Consulado de Lima, por la que tenía estipulado el fletamiento de 4.000 cabezas anuales a las tabladas de Salta, donde eran recogidas por los capataces de su socio para conducirlas al valle de Jauja. Esta alianza le facilitó el ingreso de 41.454 mulas en el mercado peruano a lo largo de una década, que se extendió entre 1700 y 1709. La conexión de Riblos con las regiones centrales del Imperio Español en Sudamérica persistió hasta febrero de 1713, cuando bajo circunstancias que intentaremos describir se vio obligado a declarar la quiebra.

Nos hemos propuesto indagar la trayectoria de una familia de terratenientes, los Riblos, para a través de ella reconstruir la historia de un latifundio a lo largo de un siglo. Partiendo de la quiebra de Miguel de Riblos, que se debió en menor parte a sus especulaciones financieras que al cambio en la coyuntura política, analizaremos la administración de sus estancias de Areco desde que fueron confiscadas por un Concurso de Acreedo-

\footnotetext{
ria agraria del Río de la Plata colonial. Los establecimientos productivos. Buenos Aires, 1993, tomo II, págs.124-208; merecen también consultarse la introducción del compilador a estos dos volúmenes colectivos y el artículo de Mayo, Carlos y Fernández, Angela: "Anatomía de la estancia colonial bonaerense", ambos en el tomo I de esta obra. Aunque sin una postura del todo definida en este debate, es útil la lectura de Saguier, Eduardo: Mercado inmobiliario y estructura social. El Río de la Plata en el siglo XVIII. Buenos Aires, 1993, sobre todo en lo que respecta a la influencia de la herencia en la rotación de la propiedad inmobiliaria rural.
} 
res hasta que, tras la muerte de aquel, fueron recuperadas y divididas por sus herederos, para finalmente ser reunificadas por Marcos Joseph, su hijo menor.

\section{La administración de Pedro de Saavedra}

Las causas de la quiebra que afrontó Miguel de Riblos en 1713 no fueron estrictamente económicas. Su fortuna hubiera podido resistir este embate, pero la coyuntura política había cambiado radicalmente. Como favorito del gobernador Agustín de Robles (1691-1700), Riblos había logrado monopolizar durante la última década del siglo XVII el comercio con las regiones vecinas, ocasionando la ruina de numerosos mercaderes de menor envergadura. Hacia fines de la década siguiente, libre de la competencia de los principales comerciantes porteños por la persecución que sufrieran durante el gobierno de Manuel de Velasco y Tejada (1708-1712), volvió a colocarse a la cabeza del tráfico interregional. Dichas circunstancias le ganaron el rechazo de un amplio sector de la élite porteña.

Con el arribo a Buenos Aires del licenciado Juan Joseph de Mutiloa y Andueza, juez pesquisidor de Felipe V, las provincias del Río de la Plata se sumaron a una nueva coyuntura política. En enero de ese año, en efecto, España había iniciado en Utrecht las conversaciones de paz con los ingleses, y se anunciaba el fin de la guerra de Sucesión. Al abrigo de este conflicto europeo, los oficiales de la Real Hacienda de Buenos Aires, en complicidad con el gobernador Velasco y Tejada, habían contrabandeado a cara descubierta con los capitanes de los navíos negreros franceses. El pesquisidor Mutiloa y Andueza, enviado por el monarca a punir estos excesos, recluyó a Velasco y sus secuaces en el fuerte y se hizo cargo del gobierno. Paralelamente a ello, declaró nulas las últimas elecciones realizadas en el Cabildo, con lo que se aseguró de que sólo ocuparan sitiales los vecinos adictos a su gestión, los mismos que habían sido perseguidos por el gobernador depuesto.

La alianza entre el pesquisidor y los nuevos capitulares, en su mayor parte adversarios de Riblos, provocaría la caída de este comerciante. En el marco de una causa por deudas que seguía contra éste un negociante gaditano, Francisco de Rivera, los coaligados consiguieron otorgar gran notoriedad a una ejecutoria contra sus bienes lanzada por Mutiloa, logrando con ello que el resto de sus acreedores, temiendo verse postergado en sus recla- 
maciones, se constituyera en Concurso. Aunque la fortuna de Riblos doblaba las sumas que se le exigían, su disponibilidad inmediata de metálico no llegaba a satisfacer el conjunto de sus obligaciones. Tratándose del mayor prestamista de Buenos Aires, es explicable que el grueso de la plata que ingresaba en sus arcas entrara en circulación rápidamente, impidiéndole responder en forma ágil a un imprevisto como éste. Pese a que ofreció sus bienes inmuebles como garantía de pago, Mutiloa ordenó al alguacil mayor Joseph de Narriondo que procediera a su arresto y encierro en la cárcel real. La quiebra fue tan inesperada y las circunstancias de la misma tan notoriamente escandalosas que, para evitar la deshonra de ser conducido en público a prisión, Riblos buscó refugio en el Colegio de San Ignacio de la Compañía de Jesús. Allí se asilaría durante más de tres años, amparándose en la condición de lugar sagrado concedida a los edificios religiosos y gozando de la protección de los jesuitas, gracias a la cual no debió temer el ingreso de oficiales de justicia. Pero no pudo evitar que sus propiedades fueran embargadas por el Concurso de Acreedores, en el seno del cual se procedió a nombrar un administrador general para las mismas.

A lo largo del proceso judicial que se le inició, sin embargo, Riblos supo explotar las contradicciones entre los concursantes, y con la manipulación del sector que le era menos hostil consiguió que fuera nombrado administrador de sus bienes uno de sus acólitos, Pedro de Saavedra, quien le permitió hacer y deshacer a su gusto en sus propiedades rurales. Contamos con tempranas pruebas de esto. Las estancias de Areco habían sido entregadas en depósito a Juan Ignacio de Samartín, quien en marzo de 1714 se vio forzado a denunciar las continuas intromisiones de Riblos. Este, en efecto, se había servido de Saavedra para relevar de su puesto al mayordomo Francisco Benencia y despedir a Domingo Cuello, capataz al cuidado de sus sembradíos. De esa forma estas fincas quedaron, al decir de Samartín, "en poder de los negros", ya que la mayordomía de las mismas recayó en Marcos, uno de los esclavos de estas haciendas. ${ }^{2}$

Ninguna medida como ésta refleja hasta que punto se conservó Riblos, pese al secuestro de sus bienes, en dominio de sus propiedades rurales. El otorgamiento de funciones directivas a sus propios esclavos constituyó un intento por aminorar los costes del embargo, evitando de ese modo que nuevas erogaciones impuestas por el Concurso, como la remu-

2 Archivo General de la Nación Argentina [en adelante AGN], Sucesión 8122, Concurso de los Bienes de Miguel de Riblos, Buenos Aires, 1713-1731 [desde aquí en más Concurso], presentación de Samartín ante el gobernador, Buenos Aires, 14 de marzo de 1714. 
neración de Saavedra (establecida en 200 pesos anuales), significaran un recorte en su patrimonio. Con ello, no obstante, no apuntó a una disminución en el personal de las estancias sino a la transformación de su vínculo con el propietario, convirtiendo al antes capataz en arrendatario. Tal fue el caso de Francisco Benencia, que levantó su población en tierras de Riblos pero no dejó por ello de asistir a su antiguo patrón, pues en 1719 se le encargó que preparara la entrega de una tropa de mulas al fletador Alonso de Alfaro. En cuanto a Domingo Cuello, las causas de su alejamiento fueron otras. Se le acusó de haber forzado a cuatro de los esclavos de la hacienda a trabajar en sus propias labranzas, maltratándolos y negándoles las herramientas para preparar las sementeras de su amo. Esta distracción de la mano de obra en beneficio propio motivó que se le reemplazara por Mateo Herrera, otro de los arrendatarios de Riblos. Poco a poco, el fenómeno del arrendamiento daría nueva fisonomía a estas estancias.

Durante la administración de Saavedra la estructura productiva de este establecimiento observó otras variaciones. Disminuyó, en primer lugar, el número de puestos de cría de mulas. Se conservaron cuatro de los seis que existieran antes de la quiebra, a partir de lo cual el territorio quedó dividido en cuatro estancias o parcelas de pastoreo: Invernada, Bagual, Sauce y Rincón. Esto permitiría la racionalización gradual de la mano de obra utilizada, aunque acarrearía paralelamente una merma en los rendimientos. Si bien la intensión de Riblos fue la de cargar sobre sus esclavos el grueso de las faenas, la utilización de negros no parece haber cubierto las necesidades de la producción, obligándolo a recurrir a la eventual contratación de peones, posiblemente no sólo para las tareas estacionales.

Aunque las estancias de Areco siguieron aplicadas a la producción de mulas, el Concurso obstaculizó durante los primeros años de la administración de Saavedra el envío de tropas a las ferias del valle de Lerma en Salta, principal mercado de ganado del Virreinato del Perú. Esta situación, empero, no estaba destinada a durar. En julio de 1717, con la llegada a Buenos Aires de un nuevo gobernador, Bruno Mauricio de Zavala (17171734), Riblos obtuvo garantías para abandonar el Colegio de San Ignacio e inició una relación más flexible con sus acreedores. A comienzos de 1719, propuso en una presentación al Concurso saldar parte de sus deudas con la venta de mulas, pues le habían llegado noticias "de la estimación con que se vendían en la ciudad de Salta". Pero su muerte, acaecida en agosto de ese año, le impidió implementar el envío de una tropa de 2.200 cabezas que tenía invernadas en Areco. 
Tras la muerte de Riblos su esposa en terceras nupcias, Josepha Rosa de Alvarado, lograría continuarle en el control (encubierto pero no por eso menos efectivo) de las haciendas. Pedro de Saavedra, que no se refería a ella sino llamándola "mi señora", la honró con la misma deferencia que a su esposo. Concluidas las gestiones iniciadas por el difunto ante el Concurso, la viuda encargó al administrador instrumentar el envío a Salta de las 2.200 mulas que se hallaban en Areco. Una proporción considerable de las mismas (el 60,86 \%) se componía de animales de cuatro años, sujetos ya a varios períodos de invernada, cuya preponderancia se debía a las complicaciones judiciales que impidieron a Riblos colocarlas con anterioridad en las ferias, forzándolo a retenerlas en sus propios puestos de engorde. No todas ellas, empero, habían nacido en sus estancias: varios de los pequeños hacendados de las inmediaciones, endeudados con este terrateniente desde antes de la quiebra, continuaron rindiéndole su cuota anual de mulas, único modo en que podían satisfacer las obligaciones contraídas. El $18,2 \%$ de las que fueron remesadas en 1719 (400 de las 2.200 cabezas aludidas) provino de la contribución de estos criadores de poca monta. Nos ilustra sobre esto el caso de dos de estos pastores, el capitán Marcos Gutiérrez Barragán y su hijo Diego. Cuando el primero falleció en 1719, se hallaba debiendo a Riblos una suma cuya magnitud desconocemos, pero que su heredero redujo a 263 pesos merced a la entrega de "yeguas y mulas". El remanente de esta deuda no sería satisfecho hasta 1726, pues en un contingente que ese año adquirió el tratante Juan Francisco de Basurco a Pedro de Saavedra se incluyeron "cincuenta mulas que pagó Diego Barragán". 3

La venta de las tropas fletadas a Salta en 1719 dejó una utilidad de 15.078 pesos, con que se saldó una parte significativa de lo adeudado por el difunto Riblos. En las dos siguientes remesas, contrariamente a la anterior, predominaron las mulas jóvenes, incluso aquellas a las que por su temprana edad era arriesgado emprender la travesía. De las mulas enviadas a Salta en 1721, en efecto, 720 cabezas (el 93,5 \% de la tropa) eran de sólo un año: requerirían al menos tres períodos de invernación en los potreros salteños antes de poder ser comercializadas en el Perú, con un insumo de $10^{1 / 2}$ reales por cabeza. Pero evidentemente, existía una urgencia manifies-

3 Las yeguas cobradas a Diego Gutiérrez Barragán ascendieron a unas 1.100 cabezas. AGN, IX-49-1-2, testamento de Miguel de Riblos, protocolizado en Buenos Aires el 6 de diciembre de 1720; Registro de Escribano [en adelante RE] n. ${ }^{\circ} 3$ de 1725-1726, testamento de Pedro de Saavedra, Buenos Aires, 9 de enero de 1726. 
ta por colocarlas en el mercado, de modo que los animales fueron precozmente confiados a los fletadores. El hecho de que se tratara de bestias de escasa resistencia motivó que estos impusieran un aumento en la "refacción" o seguro de flete, que usualmente se pactaba en el $8 \%$ de las cabezas fletadas, pero que en 1720 ascendió al $10 \%$ y en 1721 alcanzó un tope del 13\%. La primera de esas dos remesas, de 673 mulas, dejó un saldo de 3.301 pesos a favor del Concurso. La colocación de la segunda arrojó resultados menos alentadores: de las 770 cabezas que arribaron a Salta, 261 fueron adquiridas por el maestre de campo Antonio de la Torre, mientras que el resto pasó a ser invernada en un potrero de la vecina localidad de Escoypa por no habérsele hallado comprador. Deducidos los gastos de conducción y el pago del derecho de sisa en Santa Fe, la venta a De la Torre dejó una utilidad de sólo 2 pesos (!). El remanente de la tropa pasó finalmente a manos de otro tratante, Gregorio de Otálora, que pagó por él 2.437 pesos más los gastos de invernación.

La decreciente rentabilidad de estas transacciones fue atribuida a la depresión que atravesaba el mercado salteño, donde el precio del mular había descendido de 10 pesos por cabeza en 1720 a 6 pesos en 1722. Con posterioridad a este año no volvemos a tener noticias del fletamiento de tropas: las ventas se realizaron, de aquí en más, en las mismas estancias de Areco, a las que acudieron a aprovisionarse los nuevos mercaderes acopiadores. ${ }^{4}$ Todo parece indicar que hacia mediados de la década de 1720 , los Riblos habían renunciado al tráfico con las provincias del Norte, del que permanecerían ausentes durante casi veinte años.

La gestión de Pedro de Saavedra, que falleció en 1726 estando a cargo de las estancias, fue severamente criticada por quienes le sobrevivieron, en especial por Francisco de Suero, defensor de los bienes de Riblos ante el Concurso. Para éste, los rendimientos de esas haciendas habían ido en declive debido a una merma en el stock de las yeguas de cría, que se había reducido en más de 2.200 cabezas. Agregaba Suero que no había habido en dichas estancias "la aplicación y asistencia necesarias para tener sujetas las crías, retobar y amamantar burros y domar potros". Si bien la falta de vientres podía reponerse mediante una de las habituales redadas de yeguas bagualas o cimarronas, no ocurriría lo mismo con los burros hechores, cuyo

4 Se conocen las siguientes operaciones realizadas en Areco durante la administración de Saavedra: la venta de 1.350 mulas "de dos edades" al capitán Bernardo Blanco en febrero de 1725, la de 860 mulas de año a Juan Francisco Basurco en noviembre del mismo año y la de 833 mulas a Joseph Ruiz de Arellano, concertada con anterioridad a 1726. 
número había quedado también notablemente menoscabado. De los 148 que Riblos tuviera repartidos entre los puestos de cría, quedaban ahora tan sólo 45 y no se estaba tomando medida alguna para la reproducción in situ de la especie. Si se quería reconvertir las estancias en un establecimiento rentable, se imponía la adquisición inmediata de 100 burros al elevado costo de 600 pesos.

Ciertamente, la producción de ganado mular había disminuido en modo notable: en los últimos años de la administración de Saavedra la producción de mulas de las estancias de Areco parece haber llegado a su pico más bajo, entre 700 y 800 bestias herradas anualmente. No puede negarse que al seguir los lineamientos impuestos por la Alvarado, quien buscaba saldar las deudas con los acreedores y recuperar las propiedades embargadas, antepuso una verdadera expoliación de los recursos con que contaban las estancias a una planificación que contemplara su renovación a mediano plazo. Pero no deben dejar de evaluarse otros elementos sobre los que Saavedra no siempre tuvo injerencia directa. Uno de ellos fue la disminución de la mano de obra esclava, no sabemos si por venta o muerte: en 1726 sólo se conservaban cuatro de los quince esclavos que sirvieran en Areco en tiempos de Riblos. Semejante merma no fue compensada con el conchabo de peones, de los que a la muerte de Saavedra sólo había uno por estancia: teniendo en cuenta que habían quedado en pie cuatro de los seis puestos de cría levantados por Riblos, la mano de obra (esclava o conchabada) se redujo a dos personas para cada uno de ellos. Esta falta de brazos fue, sin duda, la causa del alzamiento de las yeguas de cría, lo que sumado a la extinción de los burros hechores explica en buena parte la decadencia sufrida por este establecimiento productivo. Pero también influyó en ésta la caída de precios del mular, por lo que se careció de incentivos para devolver al stock ganadero las dimensiones que poseía con anterioridad a la quiebra.

\section{La administración de Antonio Gallegos}

Tras el fallecimiento de Saavedra el Concurso designó sucesor de éste a Antonio Gallegos, uno de los acreedores del difunto Riblos. Natural del obispado de Burgos pero afincado como comerciante en Cádiz, Gallegos llegó al Río de la Plata como factor de un navío de registro y, tras establecerse en Buenos Aires, trabajó como tendero y mercader intermediario con 
las provincias del Interior. Cuando se postuló para la administración de los bienes, el Concurso de Acreedores le aceptó de inmediato, sin oposición de los herederos de Riblos. Lo extraño en este caso era su total desconocimiento del manejo de una estancia, lo que él mismo reconocía con franqueza y no motivó reparos en una ni otra parte. ${ }^{5}$ Su gestión se prolongaría hasta la disolución del Concurso y la restitución de las propiedades a los herederos en 1731.

Escasa documentación ha sobrevivido de la larga década en que Saavedra estuvo al frente de las estancias, quien fue además remiso a llevar la contabilidad de las mismas. La administración de Gallegos, aunque significativamente más breve, ha sido por el contrario pródiga en testimonios escritos, llevados a cabo con admirable puntillosidad. ${ }^{6}$ Nos hallamos ante un mirador poco común, a través del cual se nos permite conocer el funcionamiento de un establecimiento productivo desde una pluralidad de ángulos realmente excepcional. Documentación como la que dejó Gallegos es rara incluso para las estancias laicas rioplatenses del período colonial tardío.

La administración de Gallegos pasó por dos claros períodos. El primero de ellos se extendió desde agosto de 1726 a mayo de 1729. Las principales medidas que tomó en esta etapa parecen haber tendido a devolver su antigua capacidad productiva a las estancias de Areco. Esto no hubiera sido posible sin un aumento en la cantidad de brazos empleados, por lo que decidió concertar a Juan López Camelo como mayordomo y aumentar el número de peones a tres por puesto, "fuera de los cuatro esclavos que estaban en ellas". La peonada estaría sobre todo abocada a "sujetar las yeguas y domar potros para ahorrar el que continuamente se comprasen caballos". La cantidad de conchabados fue desde entonces in crescendo hasta oscilar entre los dieciocho y los diecinueve hombres entre abril y septiembre de 1728 , de los cuales quince fueron empleados como domadores. En cuanto a la falta de burros hechores, Gallegos propuso que para comprarlos se vendieran bienes de menor o ninguna utilidad, propuesta que fue desoída por el Concurso de Acreedores.

El número de esclavos se mantuvo estable a lo largo de toda la gestión de Gallegos. A los que ya existían en Areco agregó éste mulatos jóvenes

5 Dice Gallegos en una de sus cartas, refiriéndose a su falta de pericia en el ramo: "no tengo práctica ni la he tenido nunca"; AGN, Sucesión 8122, Concurso.

6 Según parece, Saavedra interrumpió la contabilidad de las estancias en 1723. Al dar cuenta de su administración, Gallegos presentó al Concurso tres cuadernos de cuentas, uno de ellos tocante al movimiento de las estancias, que se encuentra en AGN, Sucesión 8122, Concurso. 
que trajo del plantel urbano de los Riblos. El manejo de la esclavatura produjo no pocas dificultades al nuevo administrador: apenas recibido de las estancias debió afrontar la huida de dos de los morenos, mientras que encontró al resto sumido en la más absoluta indigencia, al parecer a causa de la actitud negligente de Saavedra; ${ }^{7}$ esto lo llevó a proporcionar a cada uno de ellos los géneros necesarios para la reposición de su vestuario. Los esclavos siguieron constituyéndose en la mano de obra permanente de estas haciendas. Siempre contó con seis a su servicio, lo que significó que entre abril y septiembre de 1728, momento en que dispuso de mayor número de brazos, cada puesto estuvo asistido por unos seis hombres, trátese de esclavos o de conchabados.

Disponemos de cifras con que apreciar los rendimientos de las estancias de Areco en este período. En un inventario de marzo de 1728 se detalla la existencia de 2.010 mulas repartidas entre los cuatro puestos, bien que acopiadas luego de varios años sin ventas. Al compararlo con el que se efectuara en marzo de 1713 con motivo de la quiebra de Riblos, cuando se hallaron en las estancias unos 2.032 mulares, podría concluirse que este establecimiento había recobrado su antigua capacidad productiva. Pero, al parecer, no se trató más que de un ligero repunte en la cantidad de mulas herradas por año. ${ }^{8}$ Los costos de esta recuperación, que si la hubo fue por demás efímera, fueron sin duda altísimos. Gallegos se vio ante la disyuntiva de disminuir el número de peones, del todo necesarios para mantener el stock de yeguas de cría y amansar potros y mulas, o perder buena parte de las utilidades en la paga y alimentación de conchabados. Las escasas ventas realizadas durante su gestión no acompañaron en nada sus esfuerzos: sólo tenemos noticias del transpaso de 705 mulas de 3 y 4 años "de las crías de las cuatro estancias de Areco" a favor del mercader jujeño Miguel de Olaso, efectuada en diciembre de 1728. Tampoco le favorecieron las fluctuaciones del mercado, ya que el precio del mular se mantuvo en sus índices más bajos.

7 En abril de 1727, Gallegos solicitó la venia del Concurso para gastar lo que fuere necesario en vestir a los esclavos de las estancias, "que se hallan desnudos". Unos días después se fugaba de éstas el mulato Juan Manuel, "que se hallaba cuidando con la demás gente de los ganados, con pretexto de no querer servir más en ellas", pero fue capturado y vendido a Francisco de Izarra. La situación se repitió algo más tarde con la huida del mulato Joseph. Resulta significativo que, antes de ocultarse, el esclavo Juan Manuel se presentara ante el gobernador "pidiendo venta": posiblemente Gallegos tuviera con la servidumbre una postura menos permisiva que Saavedra, con lo cual se hizo insoportable a los negros, llevando a dos de ellos al extremo de escaparse.

8 El capataz mulato Marcos afirmó que en tiempos de Saavedra se herraban entre 700 y 800 mulas por año, pero que Gallegos "sólo este año pasado [1727] había herrado ochocientas y cuarenta". 
El defensor de los bienes Francisco de Suero combatió las iniciativas del nuevo administrador y juzgó inútil el crecido gasto en peones. En realidad, no es aventurado sospechar que, coaligado como estaba con los herederos de Riblos, favoreciera el estancamiento productivo de estas estancias, pues gracias a una depreciación en el valor de las mismas éstos podrían recuperar sus derechos sobre la propiedad, haciéndolas incluir en el monto de la dote de Josefa Rosa de Alvarado. Creemos que a eso tendía cuando propuso al Concurso que fueran sacadas a la venta, alegando que las escasas utilidades no justificaban las medidas tomadas por Gallegos. Es por tanto comprensible que Suero se opusiera a que los costos de la producción se elevaran. Pretendió incluso que los cuatro puestos de cría se redujeran a dos, pero abandonó esta idea al constatar la dificultad de reconcentrar animales que ya se hallaban aquerenciados en sus parcelas de pastoreo.

Los informes de Suero al Concurso de Acreedores, por cierto, están cargados de prejuicios contra la utilización de conchabados. En su voz parece ya escucharse la de los hacendados de finales del siglo, para quienes no hubo lugar a dudas de la necesidad de estrechar el control sobre esta mano de obra díscola e insubordinada. Por las mismas causas, el defensor rechazaba los "crecidos costos de peones y asalariados que por la mayor parte lo miran todo con descuido y deslealtad aun a vista de los propios dueños" y afirmaba que "los capataces y peones siempre suponen que hacen mucho dejando perder las haciendas o administrándolas de modo que en sus salarios y alimentos se consuma todo el útil".

Gallegos acusó recibo de las críticas de Suero y procedió a deshacerse gradualmente de los peones: en marzo de 1729 conservaba sólo seis de ellos y dos meses más tarde despedía al mayordomo López Camelo, con lo que las funciones directivas volvieron a recaer en los capataces negros. Se iniciaba con esto un segundo período en su administración, caracterizado por una racionalización cada vez más acusada de los gastos. Las razones de este giro las explica él mismo en su libro de cuentas, cuando refiere haber alejado a la mayor parte de sus conchabados "por ningún aumento que se experimentaba en dichas estancias, siendo los gastos tan crecidos". A partir de entonces no recurriría a contratar peones sino en auxilio esporádico de la mano de obra esclava. Si bien nunca dejó de haberlos en las estancias de Areco, se les concertó sólo por lapsos breves que en ningún caso exce-

9 AGN, Sucesión 8122, Concurso, carta de Suero al gobernador, Buenos Aires, agosto de 1728 . 
dieron los seis meses. En diciembre de 1729, momento en que dio por concluida la contabilidad de este establecimiento, Gallegos no disponía, amén de los negros, más que de dos conchabados. Suero había logrado imponer su parecer.

¿Cuál fue la causa del fracaso de Gallegos? Se trató, sin duda, de su imposibilidad de equilibrar los pobres rendimientos del tráfico de mulas con los abultados gastos de las estancias. A lo largo de su administración, las ventas de ganado mular generaron la escasa utilidad de 1410 pesos, mientras que la sola remuneración del capataz y los peones de Areco sumó 2.415 pesos $3 \frac{1}{2} 2$ reales. El déficit sólo pudo ser saldado con la venta de inmuebles improductivos que pertenecieran a Miguel de Riblos, como sus casas en la ciudad o las tierras que éste poseyera en el Rincón de Escobar. Estos, como veremos más adelante, fueron adquiridos por un liberto de la familia Riblos, el mulato Fermín de Pesoa, quien los traspasaría a Nicolás de la Quintana, yerno de su antiguo amo. El balance negativo de la administración de Gallegos sería aprovechado por los descendientes del concursado para recuperar los bienes embargados.

Ahora bien, ¿fomentó Gallegos la gravosa presencia de conchabados con la finalidad de conducir a las estancias a su recuperación o acrecentó más bien su número para ampliar las posibilidades de incluir mercancías de su tienda en la paga de estos? Responder a ello nos conduce inevitablemente a explorar la naturaleza del "salario" que percibió la peonada de Areco mientras aquel estuvo a la cabeza de este establecimiento. No seremos los primeros en hacerlo: en su trabajo sobre lo que llamaron el "salario arcaico rioplatense", Carlos Mayo y Angela Fernández extrajeron algunas conclusiones del análisis de las cuentas de Antonio Gallegos, que intentaremos debatir aquí. ${ }^{10}$

En primer lugar, ¿cómo se componía la remuneración de estos conchabados? Mayo y Fernández afirman que todos los trabajadores recibieron metálico como parte de su paga. Esto, en efecto, es innegable: de los veintiseis peones que se concertaron con Gallegos, tanto los que permanecieron en Areco por una corta temporada como los que lo hicieron durante uno o más años accedieron en mayor o menor medida a la plata. De todos modos, preferimos ser más cautos que estos autores cuando enfatizan que el ingrediente monetario llegaba en cantidades "mayores que las sospecha-

10 Mayo, Carlos y Fernández, Angela: "El peonaje rural rioplatense en una época de transición" en Anuario de Estudios Americanos, Sevilla, 1990, tomo XLVI, págs. 305-319. 
das" a manos de los trabajadores rurales de la campaña bonaerense. El porcentaje promedio de moneda en el sueldo de estos peones era del $26,67 \%$, mientras que el $66,52 \%$ les fue abonado en especie; el administrador dejó el 6,81\% restante sin diferenciar, pues apuntó algunas partidas como "en plata y géneros". Dicho a grosso modo, las cuentas de Gallegos sugieren que dos tercios del "salario" fueron satisfechos en especie y un tercio en plata, con la salvedad de que parte de este último tercio pudo haber sido contabilizado en plata pero abonado en especie. La moneda pudo haber actuado, aunque sea parcialmente, como unidad de cuenta. Volveremos más adelante sobre nuestras sospechas al respecto.

Aunque no pueda negarse que la totalidad de los trabajadores de estas estancias recibieron en pago variables cantidades en plata, tampoco debe dejar de considerarse que todos recibieron parte de su remuneración en especie, y que la especie predominó claramente sobre el metálico. Sólo cuatro de los peones recibieron más de un tercio de su paga en moneda: de éstos, los tres que percibieron los porcentajes más altos $(46,93 ; 46,87$ y $41,04 \%$ respectivamente) eran indios. Hablar en un caso como éste de una distribución indiscriminada de la plata, que llegaría sin distinción a manos de peones españoles o de castas, implicaría una simplificación del problema. Más valdría preguntarse por qué dichos indígenas requirieron una parte significativa de su remuneración en moneda, mientras que sus compañeros blancos o mestizos accedieron a sumas mucho menores. El origen de esta diferencia ha de buscarse en el endeudamiento: los tres peones referidos conservaban dependencias con terceros que los llevaron a conchabarse, pues no tenían otra forma de satisfacerlas. ${ }^{11}$ Obviamente, ninguno de ellos estaba endeudado con el patrón de las estancias, por el sencillo motivo de que éstas no tenían estrictamente un "patrón” porque ¿quién lo era entonces: el Concurso, los herederos de Riblos o Gallegos?. Ello, empero, no resta fuerza a la idea de que las deudas podían obligar a ganapanes como estos, muchos de ellos migrados desde el interior, a permanecer empleados en las estancias. El caso de Pablo Muñoz, uno de los indios mencionados, puede servir de ejemplo: cumplido un año de haberse concertado como

11 Se trata de los indios Alocho, Diego Fernández y Pablo Muñoz. El primero se endeudó por unas espuelas, mientras que el segundo lo hizo por 24 pesos 6 reales que le prestó un tal Pedro Cuello. Muñoz, por último, se obligó con varios sujetos por 12 pesos en plata, un poncho y una espuelas. En estos tres casos, el porcentaje de plata destinado a la satisfacción de deudas fue del $24,36 \%, 88 \%$ y $52,99 \%$ respectivamente. Un cuarto indio conchabado en las estancias, Francisco Videla, insumió el $28,57 \%$ del componente monetario de su estipendio con igual fin. 
domador, "se volvió a conchabar por otros dos meses más al mismo precio de 7 pesos para pagar algunas deudas que debía". Testimonios como éste echarían abajo la hipótesis de Mayo y Fernández sobre la "ausencia de endeudamiento" en Areco, siempre y cuando no se limite este concepto a la mera situación de dependencia entre un peón y el propietario del establecimiento, teniendo en cuenta que la figura del terrateniente se hallaba desdibujada en este caso por la inusual situación jurídica en que se encontraban las estancias.

Ni siquiera Juan López Camelo, "capataz mayor" o mayordomo, constituyó una excepción a lo dicho, pues contra lo aseverado por Mayo y Fernández, también éste recibió de Gallegos "plata y géneros" en retribución a sus servicios: el hecho de que ocupara un cargo directivo no significó que percibiera la totalidad de su paga en metálico. ${ }^{12}$ A diferencia de las haciendas mexicanas, el estipendio no marcó en Areco una jerarquización en las categorías ocupacionales: ${ }^{13}$ López Camelo trabajó en las estancias durante dieciocho meses y medio, a cambio de lo cual recibió 123 pesos y esto equivale a hablar de 6 pesos 6 reales mensuales, una cantidad menor a la abonada a algunos de los domadores que se hallaban a su cargo.

Un segundo tema a tratar es el de la subsistencia misma de los peones. Es verdad que, como apuntan Mayo y Fernández, los alimentos no actuaron como componente salarial. A consecuencia de ello, éstos concluyen que "más allá de la ración, los trabajadores tenían acceso a una economía de subsistencia, o bien los compraban con su salario". Cierto es que

12 Creemos que, en su conjunto, la perspectiva de Mayo y Fernández deviene de haber trabajado las cuentas de las estancias de Riblos sin haberlas cotejado con el resto de la documentación elevada al Concurso por Gallegos. Efectivamente, en dichas cuentas se refiere que "el capitán Juan López Camelo entró de capataz mayor en dichas cuatro estancias para el gobierno y cuidado de ellas el día 21 de noviembre de 1727, ajustado a razón de 80 ps. cada año, en las que sirvió 18 meses y medio cumplidos desde dicho día hasta todo el mes de mayo de 1729, que importaron 123 ps., los que le entregué y satisfice dicho día, de que firmó recibo y salió despedido”. Sin embargo, en el recibo que firmó López Camelo al abandonar su puesto, éste expresó "haber recebido de Dn.Antonio Gallegos, como depositario y administrador de los bienes de Dn. Miguel de Riblos, ciento y veinte y seis ps. y seis rs. en plata y géneros que me ha entregado por mi asistencia y salario de capataz mayor que he sido nombrado de las cuatro estancias de Areco, propias del Concurso del dicho Dn.Miguel de Riblos" (las negritas pertenecen al autor); AGN, Sucesión 8122, Concurso.

13 Richard Garner indica que en las haciendas novohispanas de Santa Lucía y Guanamé, aquellos que ocupaban cargos directivos como los de mayordomo, "sobresaliente" y "ayudante" percibían un pago que se hallaba por encima del promedio del resto de los trabajadores rurales; a su vez, existían también entre ellos diferencias salariales que se correspondían con el mayor o menor grado de responsabilidades que se les asignaba; Garner, Richard: "Precios y salarios en México durante el siglo XVIII" en Johnson, Lyman y Tandeter, Enrique (coordinadores): Economías coloniales. Precios y salarios en América Latina, siglo XVIII. Buenos Aires, 1992, pág. 115. 
no hubo, como lo avalan dichos autores, retiros de maíz, harina, vino y azúcar: faltaría preguntarse si estos formaban efectivamente parte de la dieta alimentaria de los conchabados. Los costes de la alimentación de los trabajadores estuvieron desde antiguo a cargo de las mismas haciendas: en ese sentido, no creemos que la peonada gozara de la "independencia" que aquellos pretenden. Ya en tiempos de Riblos, las estancias habían contado con un horno de cocer pan y con novillos "para el sustento de la gente de las estancias", indicio de que la ración diaria de la peonada, además de la de los esclavos, corría por cuenta del propietario. Esta costumbre se continuó tras el embargo de los bienes. El administrador siguió proveyendo en forma gratuita al sustento de los conchabados, como se trasunta de las declaraciones de Suero, que deploraba las cantidades insumidas en su "alimentación" y diferenciaba ésta del "salario". ${ }^{14}$ Tanto el puesto del Sauce como el del Rincón disponían de cocinas, no así los del Bagual y la Invernada. La existencia en 1728 de un rodeo de 806 vacas y 810 terneras en el Sauce denuncia una dieta basada principalmente en la carne. Los demás ingredientes de dicha dieta, a excepción de la yerba y la sal, debían de ser en su mayor parte producidos en las mismas estancias; de haber sido de otro modo, hubieran sido imputados por Gallegos en los gastos generales de la administración.

La provisión de "vicios" a peones y esclavos constituye un item aparte. En los años en que trabajó como administrador, Gallegos adquirió 58 arrobas 9 libras de yerba y 23 arrobas 12 libras de tabaco para distribuir entre su gente; no hay ninguna alusión a que procediera de igual manera con aguardiente $\mathrm{u}$ otras bebidas de contenido etílico. Catorce de los peones de Areco harían retiros de tabaco a cuenta del estipendio, mientras que siete los harían de yerba: se trató siempre de cantidades escasamente significativas, que sumaron 17 libras en el primero de los casos y 89 libras 4 onzas en el segundo. Es de creer que estos "vicios", cuyo valor estimulante ha sido resaltado repetidas veces, llegaran casi siempre de forma gratuita a los trabajadores libres de estas estancias y, en lo que toca a los esclavos, con carácter de gratificación. Del volumen total de tabaco que adquirió Gallegos a lo largo de tres años, sólo el 14,11\% fue deducido de la paga de los conchabados. En cuanto a la yerba, la gratuidad en su distribución parece haber sido aún más acentuada: tan sólo el 1,04\% fue acre-

14 Ya referimos como en uno de sus informes, Suero expresaba que los "salarios y alimentos" de los peones consumían las utilidades. 
ditada en la cuenta de los peones. De la misma manera que los alimentos, el reparto de "vicios" no fue gravoso para éstos, y ya parece haberse constituido para entonces en una forma consensuada de retención de la mano de obra.

El adelanto de "vicios" a los conchabados a cuenta de su remuneración, aunque de escasa consideración, es el mejor instrumento de que disponemos para verificar qué utilidades extrajo Gallegos de la administración de estas haciendas. Las cuentas de las estancias, en efecto, expresan para la yerba y el tabaco diferentes precios de compra y de reparto, lo que nos permite discernir la política de Gallegos en lo concerniente a los pagos en especie. Este, en efecto, adquirió el tabaco a 2 reales la libra y lo menudeó entre su gente a 3 reales; de la misma manera, la yerba fue adquirida a 1/2 real pero retirada a 1 real por los peones. Por desgracia, no es posible medir de igual manera su injerencia en el reparto de textiles, dado que las cuentas no indican su precio al por mayor. Pero creemos lógica la sospecha de que obtuvo idénticas utilidades en el fraccionamiento de estos u otros efectos retirados de su tienda en Buenos Aires.

La modalidad en que se pagaba a los peones de Areco ya ha sido en parte descrita por Mayo y Fernández: mientras permanecían en las estancias, los trabajadores recibían adelantos en metálico y especie, imputados a su "cuenta salarial". Al concluir el período previamente establecido de conchabo, el trabajador bajaba a la ciudad a recibir lo que se le adeudaba. Las cuentas entre administrador y conchabado resultaron casi siempre notablemente equilibradas: sólo en un caso un peón quedó en deuda con Gallegos, mientras que en las demás ocasiones fue éste quien debió abonarles algún resto, que nunca superó los 20 pesos. Podría creerse que este ajuste final, contabilizado la mayor parte de las veces en metálico, fue realmente efectuado en moneda, pero algunas aclaraciones de puño y letra de Gallegos contribuyen a aclarar la tesitura de dichas entregas. Así, éste anota que cuando el peón Joseph Malenva fue despedido del Bagual, "bajó a la ciudad y se liquidó esta cuenta y le entregué en lo que necesitó $81 / 2$ ps. por resto y salió despedido". Fernando Laguna, conchabado por seis meses, recibió al liquidarse su cuenta "por resto de ella 10 ps. y 1 real en lo que necesitó y salió despedido". El peón Antonio de León, por último, se conchabó en la Invernada por seis meses, al cabo de los cuales se lo alejó "habiéndole entregado 7 ps. y 3 rs. por resto de ella en las cosas que necesitó". ${ }^{15}$ Queda mani-

15 AGN, Sucesión 8122, Concurso. 
fiesto que Gallegos hizo del acto de liquidar las cuentas de los peones un medio para asignarles efectos de su tienda. Testimonios como los citados nos llevan a poner en tela de juicio, si no la totalidad de las partidas contabilizadas en metálico, por lo menos las que correspondieron a la liquidación final de cada conchabado, consistentes en el 8,10\% del total de lo que éstos recibieron.

A pesar de haber actuado como un ingrediente escaso en el ingreso de los peones de este establecimiento, debe reconocerse que la paga en moneda estimuló en Areco una cierta circulación de efectos. Los retiros de metálico constituían un incentivo para el comercio menudo: las cuentas nos presentan a tal o cual peón solicitando a Gallegos unos reales para comprar, por ejemplo, una capa usada o unas espuelas de ocasión. Según se desprende de la contabilidad de estas haciendas, al menos el 20,53\% de la plata adelantada a los conchabados estuvo destinada a pequeñas transacciones como éstas, efectuadas al parecer en la Campaña. Ni siquiera los esclavos de estas estancias estuvieron excluidos de este modesto tráfico local. ${ }^{16}$ Dichas transacciones, sin embargo, no sólo fueron montadas en el numerario: también yerba y tabaco (y con toda probabilidad los textiles) fueron utilizados en las mismas como "moneda de la tierra". Gallegos indica en sus cuentas haber trocado un tercio de yerba y 2 arrobas de tabaco por una tropilla de caballos, y es posible que sus trabajadores participaran en operaciones similares.

Creemos, en fin, que hasta ahora se ha restado importancia al papel que jugó Gallegos como contratante: sólo de esa forma se explica que Mayo y Fernández pudieran afirmar que la mayor parte de los trabajadores de Areco recibieron más de un $20 \%$ de su "salario" en plata. De darse por ciertas las condiciones que acabamos de plantear, el promedio real de plata que llegó a manos de los mismos acaso ni alcanzó ese porcentaje. El hecho de que Saavedra y Gallegos aspiraran a convertirse en administradores de estas haciendas, conformándose con una paga de 200 pesos anuales abona-

16 Una partida en las cuentas de Gallegos indica que se entregaron al esclavo Basilio 5 pesos que le debía el peón Antonio de Melo. No se descarta que este movimiento de metálico entre trabajadores de una misma estancia pudiera deberse a deudas de juego; nos remitimos a ese respecto a Mayo, Carlos: "Sobre peones, vagos y malentretenidos: el dilema de la economía rural rioplatense durante la época colonial" en Anuario del Instituto de Estudios Histórico-Sociales, núm. 2, Tandil, 1987, páginas 25-32, y Martínez Dougnac, Gabriela: Persecución de vagos y cuatreros. Notas sobre la justicia colonial y la mano de obra forzosa en la campaña rioplatense, artículo presentado en la XIII Jornadas de Historia Económica realizadas en Mendoza en 1992. 
da frecuentemente con retraso, sólo puede explicarse, en conclusión, si el reparto de mercancías entre los conchabados se convirtió para ellos en una fuente de ingresos paralela. ${ }^{17}$

\section{La escisión del dominio}

Tras la liquidación de las deudas del difunto Riblos, sus herederos (su viuda Josepha Rosa de Alvarado, sus hijos Miguel, Marcos Joseph y Leocadia y el esposo de ésta, Nicolás de la Quintana) fueron restituidos en la posesión de los bienes embargados, entre los que se contaban las estancias de Areco. Tal no hubiera sido posible sin la intervención de un singular personaje, el capitán Fermín de Pesoa, "mulato cuarterón" que había nacido esclavo en la mansión de Riblos y fuera liberado por éste en 1709. El mismo alcanzaría en la década de 1720 una holgada posición económica debido a su matrimonio con Juana de Echalecu, hija bastarda del factor de navío Francisco de Echalecu. A la sombra de su suegro, miembro de una familia de comerciantes vascos establecidos primero en Cádiz y luego en Buenos Aires, este liberto participó del tráfico atlántico y amasó una fortuna considerable, en virtud de lo cual obtuvo el reconocimiento de los mercaderes españoles de la ciudad, que lo llamaron a integrar la Ilustre Junta de Comercio.

Tras la muerte de Riblos, el capitán Pesoa mediatizó la restitución del patrimonio inmobiliario de su antiguo amo en manos de sus herederos. En abril de 1721, el mulato adquirió al Concurso de Acreedores una chacra que el difunto poseyera en Montegrande, de la que hizo donación de una fracción de 600 varas a Josepha Rosa, conservando el resto del terreno para sí. Por encargo de la viuda, asimismo, inició la construcción de unas casas en dicha chacra e hizo reparar otras que ésta tenía en la ciudad. De aquí en más, Pesoa favoreció a la Alvarado con constantes desembolsos en metálico, además de costear los gastos de sus hijos, especialmente de Miguel,

17 También Saavedra realizó pagos en especie, aunque carecemos de elementos con qué determinar si estos predominaron o no sobre los pagos en moneda. Juan de Mendoza, por ejemplo, sirvió como peón por seis meses y se le entregaron por todo pago 5 varas de bayeta y 4 de bretaña; AGN, Sucesión 8122, Concurso. Es significativo que Saavedra manifestara poco antes de morir que se le adeudaban más de 600 pesos de su sueldo, amén "de los gastos hechos en los peones y demás menesteres de la administración” que constaren en su libro de cuentas; AGN, RE n. 3 de 1725-1726, testamento de Pedro de Saavedra, Buenos Aires, 9 de enero de 1726. 
futuro canónigo de la catedral de Buenos Aires, que al ingresar a la Iglesia no disponía de congrua suficiente con que sustentarse. ${ }^{18}$

Josepha Rosa y sus hijos, no obstante, no eran los únicos sucesores de Riblos. La herencia debía ser compartida con la hija mayor de éste, Leocadia, nacida de un matrimonio anterior con Leocadia de Torres y Gaete. Leocadia de Riblos había contraído enlace en 1729 con un militar español, el veedor del Presidio Nicolás de la Quintana, que, aunque manifestó interés por recobrar las propiedades de su difunto suegro, no contaba con medios para hacerlo. El capitán Pesoa se aprestó también a socorrerlo. En noviembre de 1730, el Concurso de Acreedores sacó a pública almoneda los terrenos que Riblos poseyera en el distrito rural de Escobar, una rinconada de unas 9 leguas cuadradas de superficie, que fue adquirida por el mulato para conceder al veedor De la Quintana la mitad de su territorio. Las fincas urbanas del difunto corrieron igual suerte: fueron subastadas por el Concurso y compradas por Pesoa para el dicho veedor. ${ }^{19}$

En febrero de 1731 el Concurso de Acreedores se disolvió, permitiendo por fin la asignación de hijuelas a los herederos. Dos de las cuatro estancias que componían el latifundio de Riblos en Areco, las del Rincón y Sauce, tocaron a su hija Leocadia y fueron entregadas a Nicolás de la Quintana. Los otras dos, la Invernada y el Bagual, las recibió Josepha Rosa de Alvarado en su nombre y en el de sus hijos menores de edad, Miguel y Marcos Joseph. Le fueron devueltas junto con varios esclavos, alhajas y otros objetos por un valor algo inferior al que ingresara en concepto de dote al matrimonio. Pesoa aprovechó esta ocasión para cobrarse parte de las deudas de la Alvarado, apoderándose de "todas las haciendas, esclavos y cuanto contenían" las dichas dos estancias, acción depredadora que las dejó completamente despobladas. ${ }^{20}$ Pero la actuación del liberto en las sucesivas almonedas había ahorrado a los herederos de Riblos la pérdida de sus otras propiedades rurales y urbanas. Gracias a ello, Josepha Rosa pudo esgrimir

18 AGN, RE n. 4 de 1759-1760, testamento de Fermín de Pesoa, Buenos Aires, 20 de diciembre de 1759. Allí el liberto manifiesta haber dado a la viuda "toda la plata que se le ofrecía" y contribuido a "los gastos de dicho señor canónigo cuando estaba estudiando en Córdoba y cuando pasó a Chile a doctorarse".

19 Sobre las tierras de Escobar, véase AGN, RE n. ${ }^{\circ} 2$ de 1742-1745, deslinde de tierras entre Fermín de Pesoa y Nicolás de la Quintana, Buenos Aires, 4 de septiembre de 1744. En cuanto a las casas en la ciudad, se informa en diciembre de 1730 que éstas "hoy son de dicho Dn.Nicolás, para quien declaró el capitán Fermín de Pesoa haberlas comprado"; AGN, Sucesión 8122, Concurso.

20 AGN, RE n. ${ }^{\circ} 1$ de 1770, testamento de Josepha Rosa de Alvarado, Buenos Aires, 3 de septiembre de 1768 . 
su instrumento de dote y el veedor De la Quintana el de su difunta suegra, Leocadia de Torres y Gaete, para apuntar sus exigencias a la restitución del bien más preciado, el latifundio sobre el río Areco, sin renunciar por ello a los otros inmuebles embargados por el Concurso.

Las estancias que tocaron al veedor continuaron dedicadas a la producción de mulas, mientras que las de la Invernada y el Bagual, tras la expoliación de sus recursos, permanecieron inactivas durante más de una década. Josepha Rosa de Alvarado no dispuso de medios para reponer el stock de ganados, pero se opuso a vender éste y otros de sus inmuebles rurales, y aun los defendió contra pleitos y litigios. Al no poder repoblar las estancias, la viuda optó por el arrendamiento, al que su esposo ya había recurrido desde los tiempos del Concurso. Esta vez, sin embargo, no se trataba de contar con mano de obra alternativa sino de frenar las apetencias de terceros dispuestos a cuestionar la propiedad del terreno por hallarlo despoblado. Tal era la finalidad, como lo hemos referido en otra parte, de colocar arrendatarios en los linderos de latifundios de considerable extensión como éste. ${ }^{21}$

Josepha Rosa de Alvarado afrontaría, en efecto, problemas de lindes en sus estancias. Sus vecinos inmediatos, los Sosa y Monsalve, llegaron a levantar un rancho y corrales en terrenos que los herederos de Riblos juzgaban de su pertenencia. Una primera medida de la Alvarado fue cargar de arrendatarios los linderos de su propiedad, formando un "cordón" de labradores en la periferia de sus estancias, quienes para evitar que sus sembrados fueran pisoteados ahuyentaban los ganados de los Sosa y Monsalve, causando su retorno hacia sus propias tierras. ${ }^{22}$ De esa manera, los conflictos ya existentes entre labradores y ganaderos fueron exacerbados como una forma de preservar los derechos de la terrateniente a la propiedad de la tierra.

La presencia de arboledas en estas dos estancias favoreció el ingreso de arrendatarios, la mayor parte de ellos labradores. En un pago de claro signo ganadero como el de Areco, los campesinos se vieron obligados a

21 Véase Birocco, Carlos M.: “Arrendamientos rurales en la primera mitad del siglo XVIII” en Gresores, Gabriela y Birocco, Carlos M.: Arrendamientos, desalojos y subordinación campesina. Elementos para el análisis de la campaña bonaerense en el siglo XVIII. Buenos Aires, 1992, págs. 7985, donde analizamos esa actitud en Juan Francisco de Basurco, terrateniente del pago de los Arrecifes.

22 Joseph Sambrano, arrendatario de los Riblos, declaró que los Sosa Monsalve "tenían muchas haciendas" y que él "les corría sus haciendas porque habiendo sembrado chacra le hacían daño". Gregorio Zelis también debió "correr sus haciendas por librar sus labranzas"; AGN, Sucesión 8417, Herederos de Sosa contra Riglos. 
valerse de empalizadas para evitar el avance de los animales sobre sus cultivos. ${ }^{23}$ Durante largo tiempo, los montes de árboles que a principios del siglo XVIII fueran plantados por orden de Miguel de Riblos permanecieron en pie y a ellos acudieron los arrendatarios de estas tierras no sólo para extraer palos con que "cercar sus trigos", sino para proveerse de leña y construir corrales en que encerrar sus cortos hatos de ganado. ${ }^{24} \mathrm{El}$ uso indiscriminado de este recurso terminaría por agotarlo casi por entero, completándose la deforestación cuando el arrendatario Juan de Cañas, que se asentó en las taperas de uno de los puestos abandonados, ingresó a las estancias con una gran majada. Sus ovejas, según se dice, "se comieron el monte", atacando los retoños e impidiendo que los árboles (en su mayor parte durazneros y sauces) recobraran el follaje luego de ser cortados repetidas veces.

No faltaron en las estancias ocupantes precarios que usufructuaran sus recursos. Gregorio Zelis, dueño de una situada en las inmediaciones, se adentró en tierras de los Riblos y sentó sus labranzas en las cercanías de uno de los montecillos de árboles con la finalidad de cortar palos para cercar sus "gruesas sementeras de trigo y huertas". La Alvarado, advertida de su intrusión sólo "después de pasados años", encargó al padre procurador del Colegio de la Compañía de Jesús, cuyas estancias en Areco se hallaban próximas a las de Riblos, que conminara al labrador al pago de la renta. No obstante ello, Zelis "se excusó" de hacerlo, y la Alvarado acudió entonces al gobernador Miguel de Salcedo (1734-1742), quien le ordenó bajar a la ciudad para componerse con la propietaria. Se trata de un caso típico de arrendamiento forzoso: la terrateniente, amparada primero en su alianza con otros de su clase y luego en su nexo con los más altos niveles del aparato estatal, logró quebrar la resistencia del campesino y hacerle cumplir con el arriendo, que fue en esta ocasión de 12 fanegas de trigo. La temporada siguiente, Zelis optó por abandonar las tierras de los Riblos y "mudar las chacras más afuera". ${ }^{25}$ La actitud de la Alvarado, por su parte, dejó probado que el arrendamiento, más allá de constituir una forma de asegurar los límites de la propiedad, podía actuar también como generador de ingresos.

23 Birocco, Carlos M.: "Arrendamientos...", pág. 74.

24 El arrendatario Joseph Sambrano, poseedor de una chacra, "sacó troncos y cortó leña” de duraznero, mientras que Clemente Vielma "cortaba palos del río para cercar sus trigos y hacer corrales"; AGN, Sucesión 8417, Herederos de Sosa contra Riglos.

25 Para el concepto de arrendamiento forzoso véase Birocco, Carlos M.: "Arrendamientos...", págs. 54-64. El caso de Zelis en AGN, Sucesión 8417, Herederos de Sosa contra Riglos. 
Un elemento compulsivo de incuestionable significación fue la presencia de un comisionado de justicia al que se encargó la custodia de las estancias. Se trataba de uno de los arrendatarios de estas tierras, el labrador Domingo Figueroa, quien recibió comisión del Cabildo a instancias del menor de los Riblos, Marcos Joseph, que fue alcalde de segundo voto en 1755 y regidor desde 1756 . Haciendo uso de las funciones policiales que le otorgó el Ayuntamiento, Figueroa procedió contra los vecinos más cercanos, los Sosa y Monsalve, por haber edificado un rancho y corrales más allá de los lindes de su propiedad. La situación, en un principio discretamente tolerada por la Alvarado, se tornó insostenible cuando éstos mensuraron el terreno y reclamaron como propias más de mil varas de frontada al Areco en las estancias de Riblos. Figueroa pasó entonces "de su propia autoridad" a la población de estos hacendados y demolió sus edificaciones. ${ }^{26}$ Posteriormente Marcos Joseph, que para entonces se había hecho cargo de las estancias, logró que un tribunal de justicia despojara a sus vecinos del terreno en litigio.

\section{Marcos Joseph de Riglos}

La etapa del arrendamiento llegó a su fin cuando Josepha Rosa de Alvarado cedió las estancias a su hijo Marcos Joseph para que éste volviera a poblarlas. ${ }^{27}$ Los hijos de la Alvarado variaron la grafía de su apellido y se hicieron conocer como Miguel y Marcos Joseph de Riglos. Miguel, el primogénito, que ingresó a las filas de la Iglesia, recibió las sagradas órdenes en Córdoba y se doctoró en Chile a expensas de Fermín de Pesoa, que solventó los estudios del hijo de su patrón. El doctor Riglos habría de convertirse en canónigo magistral y arcediano de la catedral de Buenos Aires y su celibato atrasaría, de hecho, la partición del patrimonio inmobiliario familiar por una generación. Las estancias del Bagual y la Invernada quedaron en manos de Marcos Joseph, su hermano menor.

Marcos Joseph de Riglos había nacido en 1719. Siguiendo los pasos de su padre, a quien no conoció, se embarcó precozmente en el comercio con las provincias del Perú. No disponía para ello de metálico, pero podía

26 Ibídem.

27 Refiere la Alvarado que las estancias estuvieron despobladas "hasta que mi hijo Dn.Marcos Joseph las pobló para sí con mi expreso consentimiento"; AGN, RE n. ${ }^{\circ} 1$ de 1770, testamento de Josepha Rosa de Alvarado, , Buenos Aires, 3 de septiembre de 1768. 
respaldar sus necesidades crediticias en los inmuebles de la familia. Provisto de este recurso, el joven recurrió a uno de los antiguos enemigos de su progenitor, Antonio de Larrazábal, quien en abril de 1742 le hizo una libranza por 3.293 pesos..$^{28}$ La carencia de liquidez que le aquejaba, empero, obligó a Marcos Joseph a incurrir en nuevas estrategias de acercamiento a las familias de mayor opulencia de Buenos Aires. En 1745 obtuvo la mano de Francisca Xaviera de Samartín, sobrina de Larrazábal e hija del maestre de campo Juan Ignacio de Samartín: aunque trababa de esa forma una alianza que su progenitor jamás hubiera aprobado, el enlace suministró a Marcos Joseph 4.000 pesos en efectivo, además de esclavos, inmuebles y alhajas que completaban la dote de su esposa. Luego de contraídas estas nupcias, que se celebraron en secreto para que sus acreedores no fueran alertados del repentino acrecentamiento de su fortuna, Riglos realizó su primera excursión comercial al Perú, seguida a los pocos años de un segundo viaje en el que recaudó "lo que había dejado el viaje antecedente". El resultado de los mismos fue exitoso: en 1752 su caudal líquido, "sin incluirse la herencia de sus padres", era de 22.897 pesos. ${ }^{29}$

En otoño de 1752, Marcos Joseph se embarcó hacia España en el navío portugués "Nuestra Señora de la Luz". Se iniciaba con ello una segunda etapa en su trayectoria mercantil, la del comercio ultramarino, que respondía a una adaptación a la coyuntura pues, durante el primer lustro de la década de 1750, Buenos Aires conoció una expansión en el volumen de intercambios con la Metrópoli. No resulta entonces casual que, siendo los cueros uno de los articuladores del renaciente tráfico atlántico, Riglos repoblase sus estancias con ganado vacuno. En un primer intento por restituir su stock de ganados, introdujo a una de ellas tres mil animales, mientras que la otra permaneció de momento despoblada.

Entre mediados y finales de la década, sin embargo, una sobreoferta de mercancías europeas provocó una grave crisis en la plaza comercial porteña. A consecuencias de ello, Riglos se volcó hacia el mercado salteño-altoperuano, por lo que reactivó en Areco la cría de mulas. Hacia 1759 ya existían allí dos puestos de estancia en los que convivían mulares y vacunos, a los que en octubre de ese año se agregó un tercero especializado en la crianza del híbrido. Riglos hizo construir en él un corral y efectuó un trato de aparcería con un hacendado del pago, Ventura de Sosa.

28 Ibídem, n. 2 de 1742-1745, escritura de obligación, Buenos Aires, 28 de abril de 1742.

29 Ibídem, n. ${ }^{\circ} 2$ de1752, escrituras de dote y capital, Buenos Aires, 8 de marzo de 1752. 
En virtud del mismo, el propietario aportó mil yeguas bagualas más "todos los pollinos que se puedan sacar de las burras que tiene, dejando a las otras dos estancias los que sean precisos", a los que Sosa añadió 450 yeguas de retajo, 30 caballos y 6 burros hechores. En lo que toca al ganado bovino, el primero contribuyó con 100 vacas y el segundo con 25 , para que se extrajeran de ellas "los novillos que sean necesarios para la subsistencia de dicha estancia". ${ }^{30}$ La contribución de los aparceros a la conformación del stock del nuevo puesto, que bautizaron "del Monte Viejo", era visiblemente desigual. Sosa se vio obligado a compensar esta desproporción con su trabajo personal: no sólo quedó a cargo del mismo, sino que se lo colocó "a la mira" de otro de los puestos de Riglos, situado en el paso del camino real sobre el río Areco. Un año después, el nuevo establecimiento contaba con dos casas, una de teja y otra de paja, y con un millar de yeguas bagualas cogidas en una redada, a las que se sumaban algunas manadas de yeguas mansas y 255 vacas y terneras. Riglos, sin embargo, protestó del "exceso de peones" que requiriera "la sujeción de dichas yeguas y construcción de la estancia", la mitad de los cuales corrió por su cuenta, de modo que obligó a Sosa a no servirse en adelante más que de dos conchabados.

El contrato que firmaron Riglos y Ventura de Sosa preveía una duración de doce años, pero la presencia del último en las estancias no parece haberse extendido más allá de 1761. La figura del capataz-aparcero, que se acomodaba bien a la etapa de repoblamiento de las estancias, no volvió a presentarse. En las siguientes décadas, las haciendas estuvieron a cargo de mayordomos: Anastasio Tapia, nacido en el pago de Areco, permaneció a cargo de las mismas entre mediados de la década de 1770 y finales de la siguiente; en 1789 le sucedió en su puesto Joseph Joaquín Bueno. Estos fueron asistidos por esclavos negros (en 1774 Riglos poseía unos veinticinco, repartidos entre sus casas de la ciudad y sus fincas rústicas) y peones.

En el último tercio del siglo XVIII, las estancias de Riglos se convirtieron en uno de los mayores establecimientos productivos de la campaña de Buenos Aires, acaso sólo superado en magnitud por los que administraban las Temporalidades. En 1774, con motivo de ofrecerlas como prenda hipotecaria de una de sus operaciones mercantiles, Marcos Joseph describió a la Invernada y el Bagual como

30 Ibídem, n. 5 de1759-1760, contrato de aparcería, Buenos Aires, 4 de octubre de 1759. 


\begin{abstract}
"dos estancias de la otra banda del río Areco como veinte leguas de esta ciudad con tres leguas de frente a dicho río y dos y media leguas de fondo, pobladas con ocho mil cabezas de ganado vacuno, cuatro mil yeguas de cría de mulas y potros y más de mil caballos de servicio de dichas estancias, dos corrales y trascorrales, con ocho mil postes de ñandubay, un cercado en la principal de dichas estancias de zanja y tuna con seiscientas varas de frente y mil y doscientas de fondo sobre el dicho río de Areco todo lleno de montes de duraznos, manzanos, olivos y otros frutales, con más las casas de una y otra estancia, todas de teja, y diez viviendas en ellas con los demás aperos necesarios de dichas estancias". ${ }^{31}$
\end{abstract}

Comparadas con otras de menor extensión, las estancias de Marcos Joseph de Riglos soportaban una alta carga ganadera. La necesidad de ampliar las tierras de pastoreo le condujo en 1789 a adquirir la casi totalidad de las fracciones desglosadas del latifundio de su padre a partir del reparto de 1731. Fallecidos el veedor Nicolás de la Quintana y Leocadia de Riblos, sus hijos y yernos consintieron en vender a Marcos Joseph las estancias del Sauce y el Rincón, incluyendo en este traspaso ganados y esclavos; esta operación se concretó con el apoyo pecuniario del canónigo Riglos, que puso a disposición de su hermano 2.000 pesos provenientes de sus rentas eclesiásticas. Sólo uno de los yernos del difunto veedor, Francisco de Espinosa y Muxica, conservó 3.000 varas de frente a la Cañada Honda, único obstáculo que impidió la completa reunificación del antiguo dominio de Riblos en Areco, cuyas nueve décimas partes recayeron desde entonces en un único propietario.

\title{
A modo de conclusión
}

El latifundio de Riblos, una rinconada provista de lindes naturales, sirvió como soporte a una tipología extensiva de explotación ganadera, el pastoreo de equinos en estado semisalvaje, de los que se seleccionaban las yeguas más aptas para la cría de mulas. No es de extrañar entonces que se le concibiera como un dominio unitario u ocasionalmente bipartito, a partir de lo cual fueron tramadas diversas estrategias familiares cuyo objeto era neutralizar la parcelación sucesoria.

Es sabido que en el Buenos Aires colonial la institución del mayorazgo tuvo un peso casi inexistente, de modo que todo caudal inmobiliario se

31 Ibídem, n. ${ }^{o} 2$ de1774-1775, escritura de obligación, Buenos Aires, 9 de diciembre de 1774. 
hallaba sujeto al desmembramiento por herencia. A pesar de que la intervención de un miembro de la clientela de la familia (el liberto Fermín de Pesoa) impidió que una porción del patrimonio inmobiliario de los Riblos fuera enajenado por obra del Concurso de Acreedores, las posteriores particiones sucesorias fueron ineludibles. Así, las estancias de Miguel de Riblos en Areco fueron divididas en 1731 entre su viuda y su yerno. La minoridad de sus hijos varones evitó una mayor atomización de las mismas, quedando las hijuelas de estos a cargo de su madre, Josepha Rosa de Alvarado.

Con posterioridad al reparto de 1731, es posible diferenciar las actitudes de los Riglos y los De la Quintana hacia el patrimonio inmobiliario rural. En lo que toca a los primeros, el ingreso de uno de ellos a la Iglesia actuó como factor retardatario en el fraccionamiento del caudal territorial. Mientras vivió Josepha Rosa de Alvarado, el conjunto de los bienes que heredaran del difunto Riblos permaneció indiviso, lo que ofreció a Marcos Joseph la oportunidad de usufructuar las fincas rústicas de la familia, contando para ello con el beneplácito de su madre y de su hermano religioso. Al morir Josepha Rosa en 1770, un acuerdo tácito entre herederos ("consentimiento recíproco proprio de su unión fraternal y buena armonía") determinó que el canónigo tomara para sí una de las casas en la ciudad, mientras que su hermano se apoderaba del resto de las propiedades inmuebles. Incluso en 1792, cuando se produjo la muerte de Marcos Joseph, este acuerdo se mantuvo en vigencia: aunque no faltaron roces entre el religioso y sus sobrinos, la viuda Francisca Xaviera de Samartín y sus hijos continuaron en poder de las fincas de la familia, entre ellas las estancias de Areco.

En cuanto a los De la Quintana, ninguno de los hijos varones del veedor mostró inclinación a hacerse cargo de las haciendas. Se volcaron, por el contrario, hacia la carrera de armas: uno de ellos, Nicolás, alcanzaría a finales de siglo el grado de comandante de fronteras de Buenos Aires. En un intento por saldar la falta de interés de sus hijos, el veedor recurrió a uno de sus yernos, Francisco de Espinosa y Muxica, al que en 1760 facultó "para que corra con las haciendas que tengo en mis estancias en el pago de Areco". ${ }^{32}$ Pero esta asociación no fue para Espinosa más que un paso previo a la adquisición de tierras propias. En 1762 consiguió que su suegro le

32 Ibídem, n. 3 de 1760-1761, acuerdo entre De la Quintana y Espinosa, Buenos Aires, 3 de diciembre de 1761 . 
vendiese 3.000 varas de frente a la Cañada Honda, primer recorte que sufrió el dominio desde el reparto de 1731. El fracaso de De la Quintana por hallar entre los suyos quien le sucediera en la administración de sus estancias hacía prever para éstas un ulterior enajenamiento. Sus descendientes, que mantuvieron el resto del territorio indiviso, lo transfirieron en 1789 en forma conjunta a su pariente Marcos Joseph de Riglos.

Marcos Joseph, al contrario que De la Quintana, contó con quien le relevara al cuidado de las estancias. Sus hijos fueron incentivados desde jóvenes para continuarle en alguna de sus múltiples actividades, de modo que hubo entre sus descendientes tanto quien le auxiliara en sus negocios como quien se especializara en el manejo de las haciendas. Uno de ellos, Rafael Joseph, participó desde joven en la administración de las fincas de la familia, aunque actuó alternativamente en el comercio y llegó a ser representante de su padre en Madrid. A los veintiún años, en 1781, se le encargó la entrega de mulas a unos mercaderes, primer testimonio con que contamos de su intervención en las haciendas. ${ }^{33}$ Desde entonces suplantó gradualmente a Marcos Joseph en el control de las fincas y, al producirse la muerte de éste, consiguió que los demás herederos le cedieran la posesión de las estancias en reconocimiento a haber asistido a su padre en la administración de sus bienes rurales durante su ancianidad. ${ }^{34}$ De esa forma, el latifundio de Miguel de Riblos conservó su integridad hasta los albores del siglo XIX.

A la muerte de Rafael de Riglos el esposo de una de sus hermanas, Mariano de Zavaleta, volvería a reunir las antiguas posesiones de Riblos en Areco por medio de compras a los descendientes de Marcos Joseph de Riglos y Francisco de Espinosa y Muxica. De esa forma, en 1813 se encontraba en su poder "todo el terreno de la testamentaria de Riblos", con excepción de 4.495 varas de frontada al Areco que Rafael de Riglos había vendido a un tal Castex. ${ }^{35}$ Un antiguo latifundio colonial rioplatense, conformado en la segunda mitad del siglo XVII, permaneció de esa manera en poder de la misma familia durante más de un centuria e ingresó al período independiente sin haber casi sufrido desmembración alguna.

33 Archivo Histórico de la Provincia de Buenos Aires, Juzgado del Crimen, 34-1-11-19, Causa criminal contra Basilio Leyba por cuatrero.

34 AGN, Sucesión 8136, testamentaría de Marcos Joseph Riglos, Buenos Aires, 1792. La fórmula utilizada por los coherederos para cederle las estancias fue la de "venta al fiado".

35 Archivo de Geodesia y Catastro de la Provincia de Buenos Aires, duplicado de mensura n. 48 del partido de San Antonio de Areco, mensura de las tierras de Zavaleta en Areco, 1813. 